\title{
A novel method using irradiated homologous cadaveric rib graft to repair an orbital roof defect following resection of a frontal ossifying fibroma
}

\author{
A Khanna, S N Unadkat, L Dimitrov, C Rennie, P M Clarke, A Aziz, H A Saleh \\ Imperial College Healthcare NHS Trust, London, United Kingdom
}

\section{Background}

Fronto-ethmoidal ossifying fibroma is a rare, benign condition(1), frequently an incidental finding on paranasal sinus imaging(2). Surgical excision is required in symptomatic cases or to prevent sequelae(3). Residual bony defects can require alloplastic grafts, with associated morbidity and recovery time.

A 16-year-old girl presented with right-sided peri-orbital cellulitis. An incidental ipsilateral frontal ossifying fibroma was discovered on imaging. This was initially resected via an endoscopic Draf III modified Lothrop procedure. Due to new bone formation, a further combined endoscopic and open Lothrop procedure was carried out at the age of 18 , with good initial outcome.

The patient re-presented at the age of 23 with diplopia and right proptosis. Imaging revealed extensive new bone formation and proptosis.
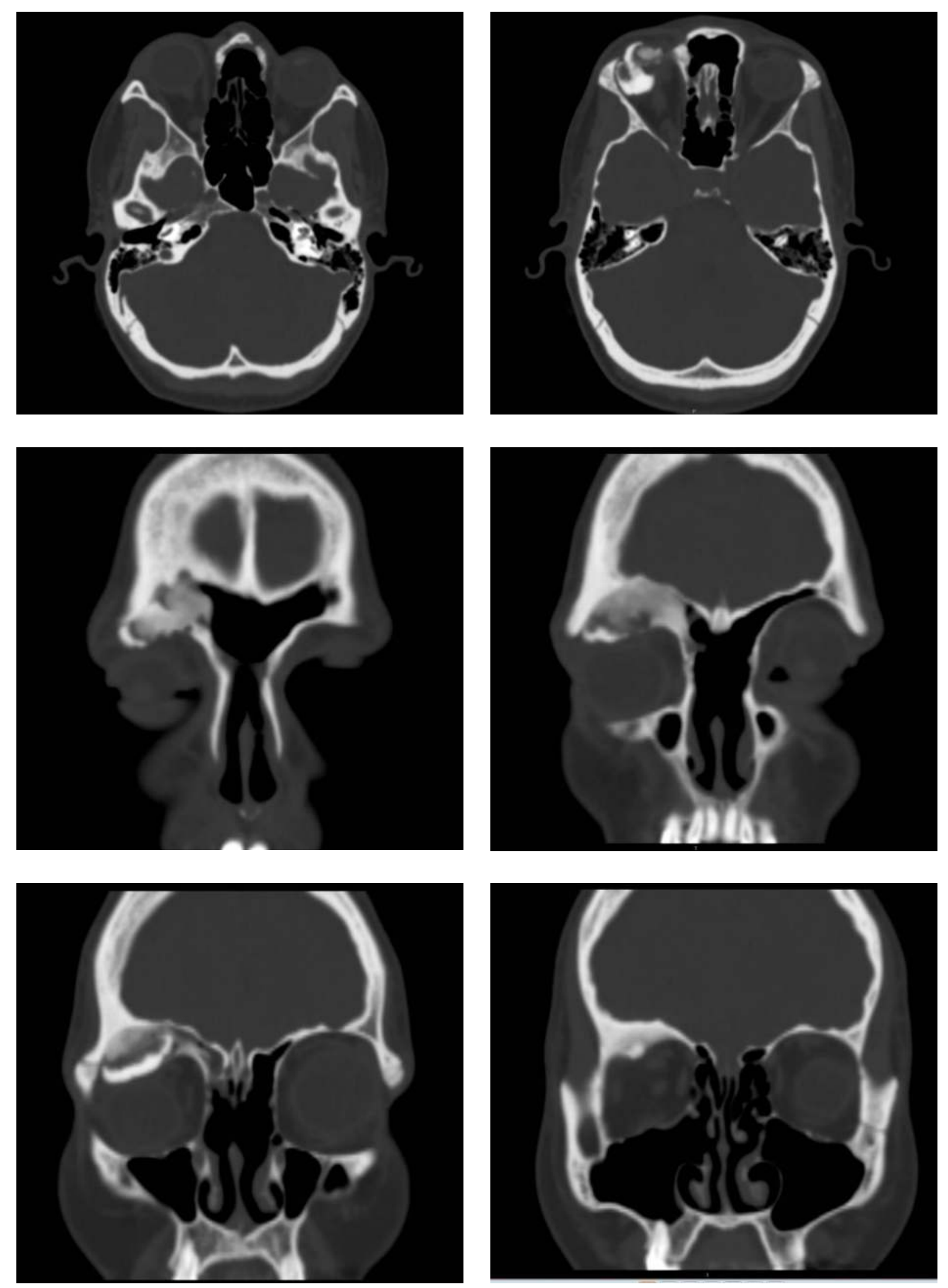

\section{Method}

The frontal sinus wall was removed via osteoplastic flap approach. The ossifying fibroma was removed from the orbital roof, leaving a $2.5 \times 3 \mathrm{~cm}$ defect. This was repaired with irradiated homologous cadaveric rib and pericranial flap overlay.
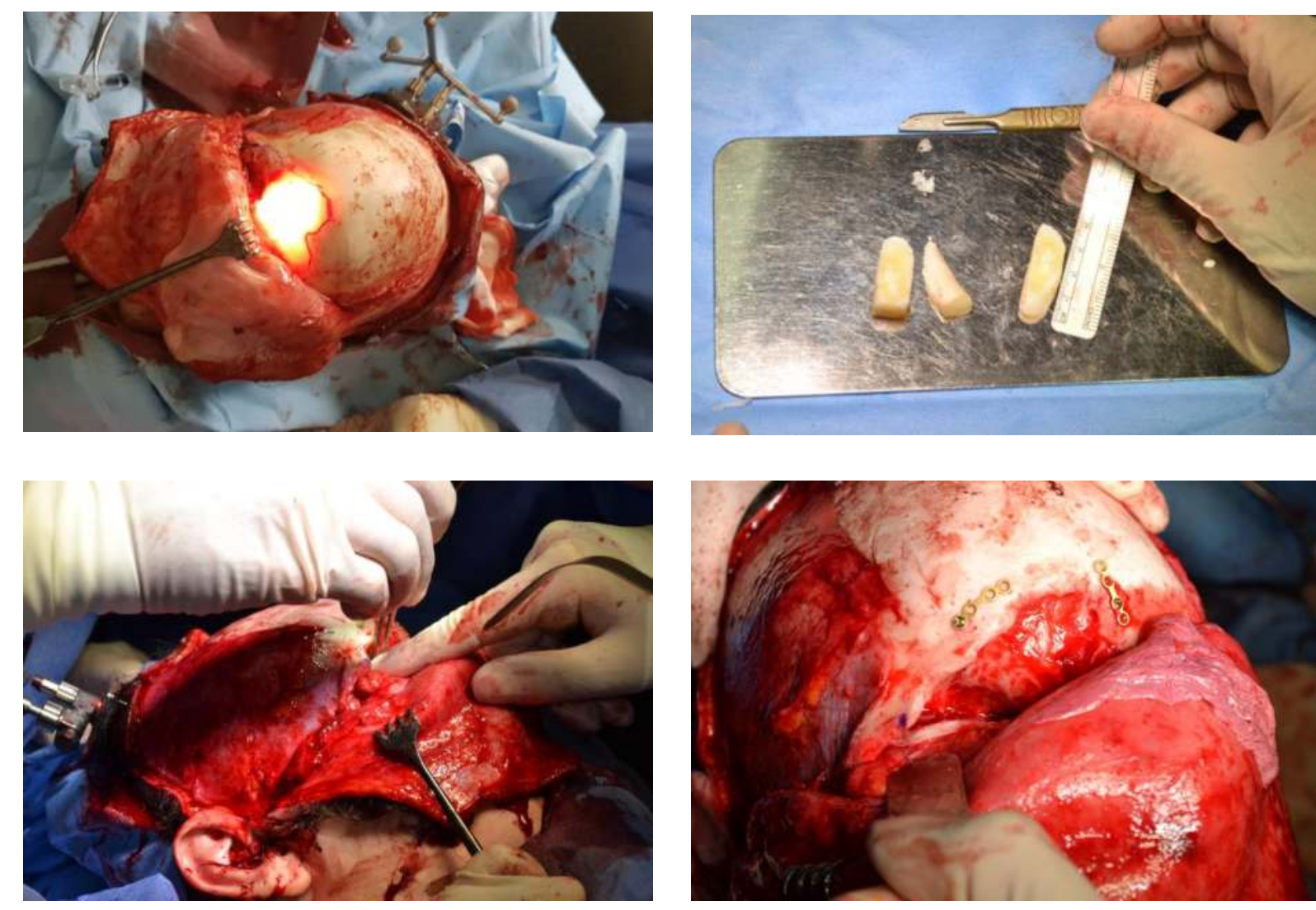

Results

Repeat imaging at four months post-operative showed improvement of proptosis and no evidence of residual disease. At six-month review, the diplopia had resolved and the patient was happy with cosmetic improvement.
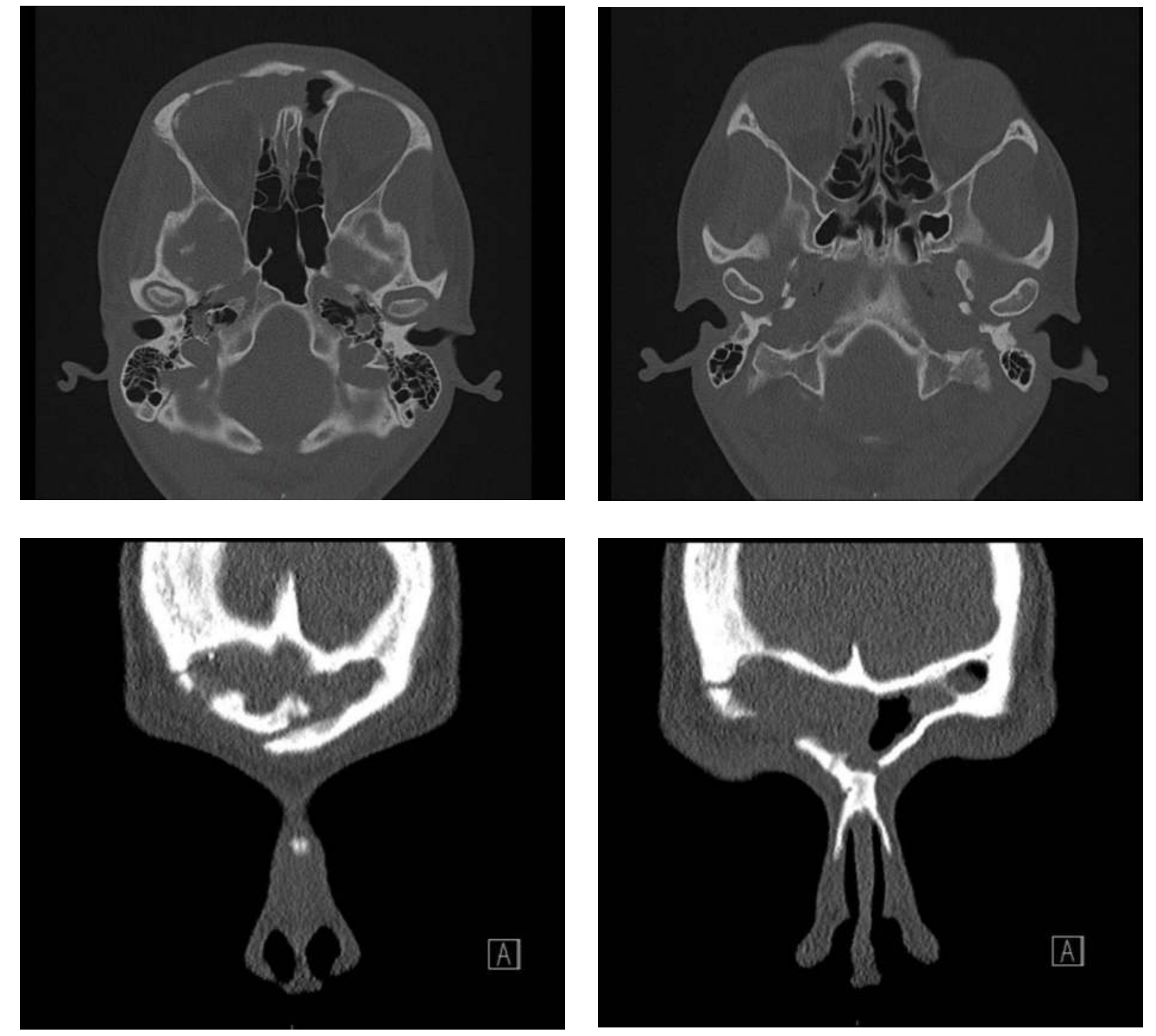

Conclusion

Irradiated homologous cadaveric rib is a viable, low morbidity graft material for orbital roof defects, negating need for painful alloplastic rib or bone harvesting.

2. Anschuetz L, Buchwalder M, Dettmer M, Caversaccio MD, Wagner F. A Clinical and Radiological Approach to the Management of Benign 